\title{
AMERICO CASTRO Y SÁNCHEZ ALBORNOZ: DOS POSICIONES ANTE EL ORIGEN DE LOS ESPAÑOLES
}

La pérdida de los últimos dominios coloniales en América hizo despertar y reaccionar a los intelectuales españoles uniéndolos, en su diversidad, en un deseo común de explicar a España. Mas la búsqueda de España no era motivada tanto por un anhelo de conocerse, como por el de justificarse. Su propio desvivirse les hacía rechazar siglos de decadencia. Trataron de buscar en el "senequismo", el "catolicismo" o en la tan matizada de romanticismo "intrahistoria", un escape para su desahogo ${ }^{1}$. $Y$ en definitiva, en sus métodos, todos hicieron suyo el lema unamuniano: "España está por descubrir, y sólo la descubrirán españoles europeizados" ( $o p$. cit., p. 141). De ahí que su descubrimiento se realizara desde afuera. Tan pronto como empezaron a escarbar en la corteza de "lo español", creyeron encontrar la esencia en aquello que sólo era una realidad parcial, aumentada por el lente del subjetivismo de sus distintas personalidades.

La Guerra Civil (1936-1939) que desgarró al pueblo español vino a probarnos la insuficiencia de los análisis de la esencia de España. Demostró lo subjetivo y unilateral de éstos y, en definitiva, el poco valor práctico de sus conclusiones en el entendimiento del ser de España. Había que variar los métodos. No sólo no era necesario, sino contraproducente, el observar a España desde afuera. Esta, en último término, sólo podría ser comprendida partiendo desde su núcleo, desde los elementos constituyentes que le dieron identidad propia. Las nuevas teorías no se hicieron esperar. Con el acaloramiento pasional consiguiente a una guerra apenas finalizada, se propuso, ideal utópico, que "el símbolo plástico más adecuado para representar la índole íntima del hombre hispánico es la figura del «caballero cristiano»"2. Más objetivos y meditados

1 Ángel Ganivet, Idearium español y el porvenir de España, 6a ed., Madrid, 1962; Ramro de Maeztu, Defensa de la hispanidad, Buenos Aires, 1952; Miguel de Unamuno, En torno al casticismo, $7^{\text {a }}$ ed., 1968.

2 Manuel García Morente, Idea de la hispanidad, Madrid, 1961, p. 217. La cita pertenece al ensayo "Ideas para una filosofía de la historia de España" 
fueron los estudios de Menéndez Pidal al tratar de comprender la existencia de "las dos Españas"3.

Hemos de esperar, sin embargo, la aparición de España en su historia (1948) de Américo Castro para encontrar una nueva y original aproximación a la realidad histórica española. Es cierto que en algunos de sus aspectos coincide Castro con Ganivet, Maeztu o García Morente, entre otros. Pero también es cierto que nunca hasta entonces se había desarrollado un acercamiento a la historia de España tan consciente y sistemático. Al igual que Unamuno y Maeztu, también él pasó de una fase "europea" a otra genuinamente "española". Y como nos dice Araya: "Dentro de la biografía espiritual de A. Castro, hay que situar en el año 1938 el momento en que hace crisis la visión europeizante de España" ${ }^{4}$. Pero incluso esta "visión europeizante" debe ser entendida de forma diferente. Las dos épocas son una sola en cuanto a su punto de partida: en la primera trata Castro de explicar lo español siguiendo el desarrollo de lo europeo; en la segunda quiso ver la esencia española como algo peculiar, y resultado de la convivencia de las tres castas que integraban la España de la Edad Media. Ambas son un ir de dentro hacia afuera:

Hasta hace no muchos años pensaba sobre este punto [la función de los árabes] como todo el mundo. Cuando en 1938 escribía un ensayo sobre ciertos problemas de los siglos Xv y xvi, noté cuán difícil era introducir lo islámico en el cuadro de la historia, o prescindir de ello, y acabé por soslayar la cuestión indebidamente... Sólo después de haber escrito mis ensayos sobre "Lo hispánico y el erasmismo" como aspectos de "situaciones vitales", comencé a ver claro el sentido de lo islámico en aquella historia ${ }^{5}$.

España en su historia, por otra parte, sólo significó el comienzo, la base para una nueva interpretación de la realidad histórica es-

(discurso pronunciado en la Universidad de Madrid en la apertura del curso académico 1942-1943). La idealización de algunos aspectos del ensayo no impide que los supuestos teóricos de éste sean un antecedente de los de la obra de Américo Castro. Sobre todo los que aparecen en los capitulos intitulados "La estructura de la realidad histórica" (pp. 146-152) y "La historia como biografía" (pp. 152-156).

s Me refiero al ensayo que apareció en 1947 como prólogo al tomo 1 de la Historia de España dirigida por Ramón Menéndez Pidal. Se publicó después con el título Los españoles en la historia, Buenos Aires, 1959.

4 Guillermo Araya, Euolución del pensamiento histórico de Américo Castro, Madrid, 1969, pp. 12-13.

5 Américo Castro, España en su historia: cristianos, moros y judios, Buenos Aires, 1948, pp. 47-48. Los ensayos que forman "Lo hispánico y el erasmismo", escritos en 1939, se publicaron en la $R F H$ entre 1941 y 1942 , y en forma de libro en Santiago de Chile, 1949, con el título Aspectos del vivir hispánico (2a ed., “con bastantes cortes y adiciones", Madrid, 1970). 
pañola, a la que Américo Castro había de dedicar el resto de su vida; que es tanto como decir los treinta años más productivos de su investigación científica. Consideremos ahora la base teórica de su concepción y la aplicación de la misma a la historia de España.

\section{LOS SUPUESTOS TEÓRICOS}

Américo Castro reaccionó desde un comienzo contra las historias tradicionales, contra el deseo desmesurado de objetividad que las hacía meras narraciones de sucesos, más o menos importantes, dispuestos en cierto orden cronológico, ya que para él, "la ingenua urgencia de narrar o averiguar sin más lo que pasó, hace olvidar a veces la auténtica realidad de los hechos y de las obras de la historia humana, una realidad sólo historiable cuando es puesta en correlación con la estructura humana en que existe, y con los valores en los cuales se hace significante"; los grandes sucesos en sí no son lo importante, sino su interrelación, su conexión en el "taller de vida" donde fueron forjados: "Los hechos humanos necesitan ser referidos a la vida en donde acontecen y existen. Esa vida es, a su vez, algo, concreto y especificado, que se destaca sobre el fondo genérico y universal de lo humano" 6 . Siguiendo esta línea de pensamiento, concluye: "La historiografía no puede cobijarse bajo una ciencia que le sirva de cúpula, rica de conceptos fijos y unívocos, al menos cuando se aspíra a hacer ver el pasado como una estructura y en una perspectiva de valor"7. "La pretensión de fundar la historia en determinaciones exactas del pasado, y en nada más, es ingenua y carece de sentido"8. De ahí nos resulta que la conjunción del sujeto agente de la historia, la estructura de los hechos humanos dentro del "taller de vida" donde se formaron y el valor de los mismos "permite construir una forma de historia en la cual mantenga la vida su dinámica movilidad; permite, además, ordenar la vida pretérita según diversos niveles de perspectiva, o sea, como meramente describible o narrable, o como legítimo tema historiográfico"9. Es decir, de nuestro pasado, de lo hecho y vivido por la humanidad, sólo una parte es y debe ser historiable. El resto es mero tema de descripción o de narración. Américo Castro nos

6 A. Castro, "La tarea de historiar", CCL, 1954, núm. 4, p. 21.

7 A. Castro, "Ser y valer: dos dimensiones del pasado historiable", CCL, 1957, núm. 24, p. 3.

8 A. Castro, "Claridad y precisión historiográfica", CCL, 1958, núm. 33, p. 6 .

9 A. Castro, Dos ensayos: 1. Descripción, narración, historiografía. 2. Discrepancias y mal entender, México, 1956, p. 11. 
define del siguiente modo cada una de estas tres categorías del pasado:

1. El nivel más bajo corresponde a los grupos llamados primitivos: son vías muertas de lo humano, marcan el paso indefinidamente. Una descripción de cómo existen basta para expresar la realidad de su vivir; sus comportamientos son fácilmente referibles a sus motivaciones: fisiológicas, psíquicas, económicas. Sus acciones duran por su reiteración (Dos ensayos, p. 23).

2. Por encima de lo que llamo espacio vital describible, aparece la vida de tipo narrable. La de ciertos pueblos -total, o parcialmente, o a trechos- es tema para la narración y nada más... Cabe dentro de la vida narrable mucho de lo denominado hoy progreso y civilización... A este tipo de vida le aplicaría el calificativo de "importante", y su forma expresiva sería la crónica o la "eventografía", no la historiografía propiamente dicha (ibid., pp. 23-24).

3. Lo historiable, sea fenómeno individual o colectivo, expresa vida total, que se afirma como vida abierta y problemática - sea como conciencia de estar existiendo, sea como respuesta clara y pensada a problemas que el existir plantea (ibid., p. 25).

Vida descriptible, vida cronicable, vida historiable: las tres se hallan presentes en el mundo de antes y en el de ahora. Hay desde luego pueblos con historia débil, o sin historia (ibid., p. 35).

Es indudable, partiendo de las anteriores definiciones, que las diferencias entre lo narrable y lo historiable son, en ocasiones, difíciles de apreciar. Incluso podríamos afirmar que han de estar forzosamente subordinadas a las preferencias específicas y al subjetivismo del historiador. Esta vaguedad en el límite de ambas categorías es manifiesto cuando el mismo Castro nos dice: "La especial y suprema forma de vida humana - historiable a la vez que narrableno cabe en los límites de la crónica. Los acontecimientos en las vidas dignas de historia, aparte de que en sí mismos sean importantes, resaltan en ellas como condición o fondo de la creación propiamente historiable" (ibid., p. 26). Los términos "especial y suprema forma de vida humana" y "vidas dignas de historia", si no sirven para determinar qué es lo historiable, sí nos indican cómo hemos de proceder para llegar a "nuestra" concepción de lo "digno de historiar": a través de nuestra propia vida, de nuestra experiencia vital. "Historiar requiere entrar en la conciencia del vivir de otros a través de la conciencia del historiador, es decir, sirviéndose de su vivencia del vivir de otros" (ibid., p. 34).

Nada más moderno, y quizás nada más legítimo y apropiado a nuestra época, que el pensamiento historiográfico de Américo Castro. Es una reconstrucción de la historia interpretada bajo una concepción de la vida muy siglo xx. Al hablar sobre España en su historia ya nos indicó José Gaos que "el método del libro responde 
a una filosofía... Es una filosofía de la historia, de la vida, una filosofía existencial"10. El peligro de tal método es que la interpretación así conseguida sea excesivamente personal, y que al perder su universalidad dé lugar a polémicas, en sí, difíciles o imposibles de conciliar ${ }^{11}$. Éste ha sido, sin duda, uno de los aspectos más criticados de la obra de Américo Castro. Sin embargo, las alas de la intuición se neutralizan al encontrarse ésta encerrada en la jaula de la "morada vital" que la condiciona y, en cierto modo, la determina: "Todo ser humano se nos aparece viviendo, en cuanto hombre, en y desde una vividura. Esta se hace presente en un modo y en un curso de vida, condicionados... por ciertas tendencias posibilitantes y por ciertas tendencias excluyentes, es decir, por un cierto modo de hacer y de no hacer, por acciones y por omisiones"12. Por ello él mismo nos previene: "No cabe hablar plenamente de historia cuando falta la referencia a una "morada» interior (vital) en donde situar los fragmentos inconexos de la realidad humana" ("La tarea...", art. cit., pp. 21-22). Con lo que se deduce que la realidad de "lo histórico" está precisamente en la conexión que existe entre los hechos y las vivencias humanas que los motivaron, sólo relacionables a través de una "morada vital".

La originalidad de las ideas expuestas por Américo Castro, y la constante necesidad de fundamentar éstas por medio de supuestos teóricos, le obligaron a proponer una nueva terminología que pudiese expresar en forma más perfecta lo complejo de su pensamiento. Así se originaron expresiones como "vivir desviviéndose"13, "morada vital", "vividura" y las ya anotadas de "lo describible, lo narrable y lo historiable". La base de todas ellas quizás haya de encontrarse en "la morada vital", cimiento de todo este edificio

10 José Gaos, “España en su historia”, $C u A, 1949$, núm. 5, p. 213.

11 Gilman nos describe así el proceso seguido por Castro en el historiar: "He doesn't begin with observation of facts but with what is called eintuition" and what used to be called cappreciation*. Or, to use an even older and truer word about man's relation to values, Castro "loves" before he observes" (Stephen Gilman and Roy Harvey Pearce, "The structure of Spanish history", Explorations, 6, 1956, p. 33).

12 A. Castro, Ensayo de historiología: analogias y diferencias entre hispanos y musulmanes, New York, 1950, p. 10.

13 A. Castro, La realidad histórica de España, 4a ed., México, 1971, p. 80, define el término del siguiente modo: "Muchos desearían que esa historia [la de España] hubiese sido de modo distinto de como fue porque la vida de España hace siglos que viene consistiendo en un anhelo de edesvivirse», de escapar a sí misma, como si la vida pudiese desandar su camino. El «desvivirse» se refiere en este caso a la insatisfacción de la propia vida, a preguntarse si de veras se ha alcanzado la finalidad que se perseguía, o si es posible alcanzarla... Se vive entonces como si la vida, en lugar de caminar hacia adelante, sintiera la necesidad de desandar, de comenzar nuevamente su curso". 
histórico. Veamos lo que el término significa para su autor ( La realidad..., pp. 109-110) :

Parto de la convicción de haberse formado el pueblo español y de haber surgido a la vida historiable en enlace con situaciones casi siempre muy apretadas y desapacibles.

Tuve así que construir una figura historiable en la cual cupiesen tanto los desarrollos valiosos como los opuestos a ellos. $\mathrm{He}$ tomado como centro y agente de esta historia el taller de vida en que la españolidad fue fraguándose, y no parciales rasgos psicológicos, siempre genéricos e inconexos; no he pensado tampoco en que las circunstancias exteriores fueran algo aislable del curso mismo. de la vida, como si ésta fuese una realidad ya previamente dada sobre la cual cayeran causas o motivos. La vida historiable consiste en un curso o proceso interior, dentro del cual las motivaciones exteriores adquieren forma y realidad; es decir, se convierten en hechos y acontecimientos dotados de sentido.

Estos últimos dibujan la peculiar fisonomía de un pueblo, y hacen patente el "dentro" de su vida, nunca igual al de otras comunidades humanas. Mas este "dentro" no es una realidad estática y acabada, análoga a la sustancia clásica; es una realidad dinámica, análoga a una función o, como indicaré luego, a una invariante. Pero el término "dentro" es ambiguo: puede designar "el hecho de" vivir ante un cierto horizonte de posibilidades y de obstáculos (íntimos y exteriores), y entonces lo llamaré "morada de la vida"; o puede referirse "al modo como" los hombres manejan su vida dentro de esta morada, toman conciencia de existir en ella, y entonces lo llamo "vividura". Ésta sería el modo "vivencial", el aspecto consciente del funcionar subconsciente de la "morada".

\section{Aplicación a la mistoria de España}

Los mismos supuestos teóricos de Américo Castro nos indican que su historia no va a ser un estudio sistemático del pasado español. Tampoco pretende cubrir todo lo sucedido en la Península ibérica desde las primeras civilizaciones que la habitaron. Por otra parte individualiza, hasta el extremo, la peculiaridad española, aislándola del resto del mundo occidental: "El curso de la vida española ha sido muy diferente de la del resto de los pueblos europeos" (Dos ensayos, pp. 48-49). Para Castro esta diferencia radica, primariamente, en la convivencia de cristianos, moros y judíos: "Los cristianos del norte no pudieron forjarse una cultura a tono con la cristiandad europea... precisamente a causa del sistema de las tres castas, cuyo análisis y valoración es el tema de esta obra mía" (La realidad..., p. 196). Si, como queda indicado, el punto de partida para todo conocimiento histórico es la "morada vital", 
la búsqueda de ese comienzo del saberse existir español ha de ser el principio forzoso, puesto que ella está integrada por "la presencia de un grupo humano, consciente de sus dimensiones colectivas y territoriales, de un pasado sentido como vivo..., consciente también de un futuro prometedor de bienes o preñado de males" (ibid., p. 126). Por ello, al hablar de los godos, niega a los habitantes de la España de aquella época su calidad de españoles, ya que vivían "sin acabar por reconocerse, ellos mismos, como plenamente existentes y dignos de historia" (ibid., p. 156). De ahí que pueda asegurar categóricamente: "Los castellanos y aragoneses no eran ni visigodos ni romanos ni celtíberos, porque la dimensión colectiva de un grupo humano depende de una forma social y no de una sustancia biológico-psíquica, latente y perdurable" (p. 145) . Es decir, hubo una morada vital hispano-goda (para Castro los godos se sentían ser godos viviendo en tierras de España), lo mismo que anteriormente había existido otra hispano-romana. En resumen, su historia "se funda en el supuesto de que la conciencia de ser español y de estar obrando como tal comienza a hacerse sentir entre los siglos x y xI, porque ser español y ser habitante de la Península ibérica son cosas distintas" (p. 139).

Lo que Castro nos propone es algo nuevo y digno de ser meditado. Según él, ni Vidriato, ni Séneca, ni San Isidoro de Sevilla pueden ser considerados como españoles, si este término ha de servir para algo más que para designar a los habitantes de España. No fueron españoles, porque su morada vital no era la misma de aquellos que luego comenzaron a llamarse y sentirse españoles: "La morada vital de los futuros españoles hubo de alzarse, desde el siglo viII, sobre ruinas e incoherencias humanas de espesor excepcional" (Dos ensayos, p. 32). La venida de los árabes a España supuso algo más que la conquista, más o menos prolongada, de casi la totalidad de la Península: "El Islam obligó a contemplar y a usar en una nueva perspectiva el tradicional modo de existir y el quehacer social de los habitantes del norte" (La realidad... p. 176). Si la morada vital de los españoles comenzó a formarse en el siglo vili, todo lo anterior, según. Castro, cae fuera de los límites de la verdadera historia de los españoles. La cual, por otra parte, ha de basarse en la determinación de cuándo y cómo surgió dicha morada vital. Una vez fijada ésta, el modo vivencial de los españoles, o sea "el aspecto consciente del funcionar subconsciente de la morada", estará motivado $\mathrm{y}$, en cierto modo, condicionado por ella misma. De ahí que Américo Castro limite su estudio a la Edad Media y a algunos aspectos del vivir hispánico del siglo xvi.

Opuesta a estas teorías, a pesar de numerosas e interesantes coincidencias, se halla la concepción historiográfica de Claudio 
Sánchez-Albornoz, gran medievalista y, sin duda, la figura más notable y mundialmente reconocida de la historiografía actual española ${ }^{14}$. Su preocupación por el "ser de España" tiene una manifestación primeriza, en forma balbuceante, en su réplica a la aparición de España invertebrada: "España y Francia en la Edad Media, causas de su diferenciación política"15. Pero fue en 1929 cuando en un sugestivo ensayo, "España y el Islam", mostró decididamente su posición ante la función de la Edad Media en la forja de lo español ${ }^{16}$.

Sánchez-Albornoz, como años más tarde lo haría Américo Castro, reaccionó contra el tan repetido postulado de Ortega y Gasset: "Es oportuno advertir que ni los árabes constituyeron un ingrediente esencial en la génesis de nuestra nacionalidad, ni su dominación explica la debilidad del feudalismo peninsular"17. Su pensamiento no podía ser más opuesto, pues para él "éste fue el minuto decisivo de la vida de España" (España y el Islam, p. 14). Y por ello afirma: "La psicología castellana [fue] formada despaciosamente a través de muchos siglos de batalla con el moro" (p. 42). Su defensa entusiasta le llevó a emitir juicios que más tarde trataría de combatir en la obra de Castro. Cautivado por las investigaciones de los arabistas españoles y subyugado por la civilización hispano-árabe, no duda en afirmar: "Ellos han reivindicado para la España islamita una participación, decisiva, en el desenvolvimiento del arte, de la filosofía, de la ciencia, de la poesía y de toda la cultura europea medieval" (p. 17; el subrayado es mío). Creía que las pruebas de este florecimiento de la España islamizada eran ya sobradas, "aunque más allá y más acá del Pirineo y del Mediterráneo no se resignen a admitir sin combate este maestrazgo hispano-árabe" (p. 18). De todos modos, no debemos olvidar que si bien Sánchez-Albornoz decía que "los españoles islamizados crearon una civilización y una economía esplendorosas" y que "Hispania se compenetró pronto con aquella nueva cultura" (p. 17), consideró esta influencia per-

14 En 1970 le fue concedido el premio internacional "Antonio Feltrinelli". Se le presenta así (apud Claudio Sánchez Albornoz, Miscelánea de estudios históricos, León, 1970, p. 547): "Storico fra i maggiori della Spagna, della stessa generazione di Ramón Menéndez Pidal e maestro riconosciuto di quanti in Spagna, in Europa e nell'America Latina si interessano alla storia spagnola nelle sue relazioni con la storia medievale e moderna dell'Occidente... La sua opera storica ha un posto eminente nella storiografia internazionale degli ultimi cinquanta anni per la quantità degli studi, per la varietà degli interessi e dei campi di indagine esplorati, per l'originalità e la felicità della ricerca e della ricostruzione".

15 ROcc, 1923, núm. 2; ensayo reproducido en España y el Islam, Buenos Aires, 1943, pp. 143-180.

16 ROcc, 1929, núm. 24; reproducido en España y el Islam, pp. 11-20. p. 129 .

17 José OrTega Y Gasset, España invertebrada, $2^{4}$ ed., Madrid, 1967, 
niciosa y el origen de todos nuestros males, pues el Islam "torció los destinos de Iberia" (p. 15). Sin él, "España hubiera seguido los mismos derroteros que Francia, Alemania e Inglaterra; y a juzgar por lo que, a pesar del Islam, hemos hecho a través de los siglos, acaso hubiéramos marchado a su cabeza" (ibid.). Es decir, la influencia, o mejor dicho, la importancia de lo islámico no está sólo en la simbiosis cultural, sino también, y quizás con más fuerza, en la reacción de la España cristiana contra lo musulmán. SánchezAlbornoz considera ambos aspectos como negativos, a la par que decisivos en el desarrollo posterior de España: "Dañosa fue asimismo a la economía hispana la superexcitación guerrera que padecíamos a consecuencia de la lucha con el Islam. Ella separaba mucha parte de la actividad hispana de la vida económica, inclinándola hacia el ejercicio de las armas..., y este permanente apartamiento de las tareas de la paz, de los más osados y de los más audaces, privó a la industria y al comercio peninsulares de aquel espíritu de empresa que produjo la grandeza económica de las ciudades italianas, flamencas, francesas" (p. 37). El problema, pues, es el mismo que después planteará Américo Castro; las consecuencias son también semejantes. Las causas que dieron lugar a tal situación, sin embargo, son muy diferentes en ambos historiadores: mientras para Sánchez-Albornoz fue una consecuencia de la lucha multisecular contra los moros, continuada después en el siglo xvr por el descubrimiento de América, Américo Castro encuentra sus orígenes en la intransigencia social y luchas de las tres castas, cuya prolongación se extiende igualmente a los siglos xvr y xvII.

Consciente de las ideas, en ocasiones extremas, expuestas en España y el Islam, Sánchez-Albornoz escribía años más tarde: "Yo mismo, no obstante mi convicción acerca de lo poco que sabíamos de la historia española, me atreví... a publicar, en un brevísimo ensayo histórico literario, que titulé España y el Islam, mis pobres conjeturas de entonces sobre la acuñación de la herencia temperamental de los hispanos"18. Una mayor madurez en el estudio de lo histórico, conseguida a través de una vida dedicada a la investigación de nuestro pasado, y su oposición a toda teoría que para describir el carácter español se base sólo en ciertos aspectos del pasado histórico, explica su pronta reacción ante la publicación de España en su historia.

En el "prefacio" a su obra España, un enigma histórico y bajo el título de "El porqué de este libro", con una sinceridad que le honra, explica Sánchez-Albornoz: "Sin la aparición de España en

18 Claudio Sánchez Albornoz, España, un enigma histórico, Buenos Aires, 1956 , t. 1 , p. 11 . 
su historia yo habría aún tardado muchos años en decidirme a escribir una obra tan ambiciosa como ésta...: la audacia de Castro suscitó la mía" (t. 1, p. 12). Su obra, sin embargo, no es simplemente una nueva interpretación de España. Es una obra polémica: "Vacilé mucho antes de lanzarme a una empresa pareja de la por Castro acometida. Mas el temor de que sus teorías pudieran convertirse en básica interpretación de la historia española en las décadas próximas... y mi apasionada devoción por la verdad, me decidieron a examinar de nuevo y despacio el enigmático problema de España, y a publicar al cabo mis reflexiones sobre él" (ibid.). Consideremos ahora brevemente sus principios teóricos y su aplicación a la historia de España.

\section{LOS SUPUESTOS TEÓRICOS}

La posición de Sánchez-Albornoz, cuya evolución es paralela al desarrollo de la historiografía española, podría caracterizarse con las palabras de R. B. Tate: "Sigue sustancialmente cerca de la tesis enunciada por Menéndez Pidal"19. En efecto, enemigo de las teorías fantásticas, ya desde un principio nos ṕreviene: "No he de apartarme del camino real aunque haya sido recorrido con frecuencia, pues no desdeño la verdad porque sea vieja conocida de muchos, ni me seducen las novedades engañosas, cualquiera que sea el atractivo de su frescura juvenil. Prefiero cabalgar la parda mula del buen sentido que el pura sangre de la imaginación desenfrenada" (España, un enigma..., t. 1, p. 19). Su interpretación, paradójicamente, resulta en cierto modo nueva. El "ser español" que nos presenta está más de acuerdo con la complejidad de lo español que la raíz senequista de Ganivet, el cristianismo de Maeztu y García Morente, el elemento godo de Ortega y Gasset o la convivencia de las tres castas de Américo Castro. Sánchez-Albornoz consideró todos estos aspectos, pero nunca pretendió elevarlos a un plano dominante con exclusión de los demás. De ahí que resulten tan acertadas las palabras de Rosa Zuluaga, discípula suya, cuando al resumir su postura dice: "Su eclecticismo historiográfico es la resultante de su adentramiento en los intrincados dominios de la vida histórica de los pueblos. El profundo y continuo análisis de la realidad le ha enseñado a ponderar, en real medida, la participación de los elementos y fuerzas concurrentes en la vida de las comunidades humanas" ${ }^{\prime 20}$. Sí, un eclecticismo historiográfico, pero

19 R. B. TATE, "Medieval literature", The year's work in modern language studies, 19 (1957), p. 186.

20 Rosa Zuloaga, "Ia postura historiográfica de Claudio Sánchez Albornoz", CuHE, 1960, núms. 31/32, p. 293. 
no un eclecticismo conciliante de teorías opuestas, sino un considerar todos los aspectos que intervienen, activa o pasivamente, en la formación de la "morada vital". Ésta es la verdadera constante en los postulados teóricos que el autor reúne en el capítulo primero de su libro: "Se ha negado que la geografía rija el curso de la vida histórica. Suscribo esa negación, pero no me permito prescindir de la influencia ejercida por el medio geográfico en el acuñarse de la personalidad de cada pueblo" (España..., t. 1, p. 13). "No cabe ver en el curso del pasado la pura acción de necesidades y de apetencias materiales; pero el modus operandi de cualquier comunidad humana no ha podido madurar en un puro mundo de ideas, desprendido de todo contacto con la tiranía eterna del vivir" (ibid.). "No menosprecio lo lingüístico ni lo literario como motor y expresión de lo histórico, pero no puedo prescindir de los marcos institucionales -sociales y políticos- dentro de los cuales ha madurado la vida de los pueblos" (1, 13-14). Su amplia visión abarcadora del complejo histórico resulta ecléctica incluso cuando se opone a superadas teorías hasta ayer vigentes: "Aunque no soy positivista, miro a lo biológico como factor activo en las creaciones humanas y de la vida histórica" $(1,13)$. Sabe muy bien que no "es lícito limitar el ámbito de lo histórico al estudio de los hechos singulares" $(1,37)$. Pero ello no le hace desdeñar la erudición: "Los hechos no son la historia, pero no puede hacerse historia prescindiendo de ellos" (1, p. 13).

En resumen, para Sénchez-Albornoz la historia no debe "limitarse a estudiar estos o aquellos hechos; tiene que enfrentarse con cuantos integran el complejo tejido de la vida y de la cultura del ayer" $(1,39)$. El historiador, por otra parte, no presencia los hechos que va a historiar, por lo cual debe ser consciente de que ha de añadir "al subjetivismo de su visión el subjetivismo de los hombres cuyos testimonios aprovecha. $\mathrm{Y}$ ese doble o triple filtro que se interpone entre los acontecimientos históricos y las páginas de la historia, necesariamente ha de dificultar el trazar de éstas" $(1,24)$. Una vez establecidos estos postulados preliminares, pasa el autor a considerar la historia como el resultado de tres fuerzas: a) "la contextura vital de la nación abocetada, ya en la prehistoria, pero siempre dinámica y en perpetua mudanza"; b) "los conductores del pueblo, de talla diferente pero siempre moviéndose entre las tensiones encontradas de la herencia temperamental del grupo humano en que han nacido"; c) "el azar -los antiguos habrían dicho Fortuna-, fuerza ciega, difícil de concebir y de explicar por quienes no creen en la acción creadora y rectora de la vida por una potencia divinal" $(1,61)$. De este modo, por caminos diferentes, Américo Castro y Sánchez-Albornoz llegan ambos a una concepción semejante, que aquél llamó "morada vital" y éste denomina 
"contextura vital". La "contextura vital" sería estudiada por la "historia horizontal", mientras que su evolución y proyecciones en el tiempo sería objeto de la "historia vertical", la cual "sólo es concebible en permanente conexión con la historia horizontal de las comunidades culturales y vitales de que ha ido formando parte activa al correr de los tiempos" $(1,35)$.

\section{Aplicación a la historia de España}

Sánchez-Albornoz compara la historia con un río: “ ¡El río de la Historia! Ningún símil es perfecto, pero éste no es demasiado aventurado" $(1,64)$. Nada más acertado para poder explicar con brevedad el sentido de su oposición con Castro. Por ello dirá con desenfado: "Me he alzado contra la absurda y torpe teoría de que lo español es posterior al 711. Es difícil evitar una sonrisa ante la afirmación -de un tan exquisito ensayista como peregrino historiador- de que todo lo ocurrido en la Península antes de la invasión islámica cae fuera de la historia de España" $(1,5)$. En efecto, Sánchez-Albornoz, al igual que en el río, ve los principios de nuestra historia en los primitivos habitantes de España. Esta postura ha motivado que sus lectores precipitados, o aquellos que sin leerle le critican $^{21}$, le hayan acusado de presentar un "ser español" invariable desde Viriato hasta el siglo xx: "Sólo con perversa intención confusionista puede presentárseme sosteniendo la perpetuación a través de milenios de una y la misma españolía: la existencia del homo hispanus con sus caracteres esenciales en el hombre de la Cueva de Altamira y su prolongación sin variantes hasta nuestros días" $(1,5)$. Es muy comprensible su enojo, más después de haberle oído repetir infinidad de veces a lo largo de sus obras que "lo español ha ido madurando muy despacio y que sus raíces más profundas toman sus jugos en los más viejos tiempos del pasado peninsular" $(1,6)$. Por otra parte, su diferencia más notable con Castro estriba, precisamente, en ello: mientras éste afirma que la morada vital de los españoles se formó en su perfección durante los siglos medievales, y que permanece apenas sin variación hasta la actualidad, a Sánchez-Albornoz no le "parece lícito prescindir de las huellas de lo premuslim en la España musulmana" $(1,13)$. Y

21 Me refiero aquí a los escritos pasionales de Claudio Guillén, "En torno a Santiago de España de Américo Castro", $R H M, 25$ (1959), 207-217, y de Juan Goytisolo, "Supervivencias tribales en el medio intelectual español", en Estudios sobre la obra de Américo Castro, Madrid, 1971, pp. 143-156. Con referencia al artículo de Guillén, véase la respuesta de HiLda Grassotti, "Plática escuderil: en réplica al ataque de Claudio Guillén a Sánchez Albornoz", CuHE, 1960, núms. 31/32, 250-274. 
si bien ve en la reconquista la "clave de la historia de España" $(2,9)$, cuya "empresa multisecular constituye un caso único en la historia de los pueblos europeos" $(2,11)$, se apresura a afirmar: "No tengo por conclusa la fragua de la contextura temperamental de ninguna nación en ningún momento de su historia, y por ello no puedo prescindir del golpear del martillo de la Modernidad sobre el yunque de nuestro Medioevo en la forja de lo hispano" $(1,14)$.

La publicación de España en su historia (1948) inició una nueva época en la interpretación del ser español. Por lo peculiar de sus postulados y la intrepidez de sus conclusiones, promovió de inmediato una acalorada polémica. Sánchez-Albornoz, representando en cierto modo a los historiadores, hizo causa personal el combatir las teorías de Castro, no sólo refutando aquello que le parecía erróneo, sino proporcionándonos también su propia versión del pasado español. La polémica, dentro de los mejores términos académicos en su comienzo, llegó con los años a convertirse en agria e injuriosa, salpicada de mutuas acusaciones.

Las primeras intervenciones de Sánchez-Albornoz fueron sobre aspectos ya en polémica. Así su artículo “¿De los 'banu al-ajmas' a los fijodalgo?" (1951), donde ampliaba el tema tratado por Leo Spitzer y A. Nykl entre otros, y respondía a dos artículos sucesivos de Castro: "Antiguo español fijodalgo-ibn-al-homs" (1950) y "Con motivo de fijodalgo" (1951). Sobre este particular habria de volver más tarde en España, un enigma histórico, dedicándole una sección en el capítulo cuarto: "No se arabiza la contextura vital hispana". Aquí dejaba como solucionado el problema sobre tan discutida etimología. Américo Castro, sin embargo, volvió al tema en 1961 con una afirmación categórica, y en su pensar definitiva, en el artículo "Hijodalgo, un injerto semítico en la vida española" 22.

La verdadera confrontación se efectuó en 1953, cuando SánchezAlbornoz publicó su enjundioso artículo "Ante España en su historia", silenciado después por los discípulos de Castro ${ }^{23}$. En la introducción del artículo se señala claramente que la crítica al libro de Castro se hace con la esperanza de que "le mueva a modificar sus viejas teorías, ahora que se dispone a retocarlas". Sánchez-Albornoz

22 Véanse los datos pertinentes en la Bibliografía que publico al final.

23 C. SÁnchez Albornoz, "Ante España en su historia", CuHE, 1953, núm. 19, 129-145. Cuando se publicó la colección de ensayos de Américo Castro, Semblanzas y estudios españoles, Princeton, 1956 (libro-homenaje), Albert Brent y Robert Kirsner compilaron una bibliografía que pretendia ser "lo más completa y exacta posible"; en ella incluyeron reseñas y comentarios de periódicos y revistas (a veces de poca importancia), pero no ése de Sánchez Albornoz. 
recalca además: "No me he aventurado a escribir estas páginas con ánimo hostil... Deseo vivamente que "las cañas no se tornen lanzas» y he de esforzarme para lograrlo". La realidad es, sin embargo, que el artículo en cuestión pretende destruir la obra de Castro. De seguir las indicaciones en él anotadas, el resultado nunca podría ser una "modificación", sino una "nueva interpretación". "Ante España en su historia" puede y debe ser considerado como una anticipación de lo que después habría de ser España, un enigma histórico. El esquema del artículo es simple, a la vez que categórico. Comprende cuatro partes: a) "Asentimientos y reservas", donde se precian algunos de los postulados de Castro, que son en sí insignificantes en cuanto a la tesis fundamental de la obra; $b$ ) "Falsas premisas", donde se rechazan, una por una, las premisas históricas más importantes en que se fundamenta esa obra; c) "Errores de método", donde se critican determinados puntos o se recuerdan aspectos olvidados; d) "Menosprecio y exaltación de fuerzas generadoras de la historia", donde se acusa a Castro de no considerar, entre otras cosas, la geografía, el valor de la historia económica y el factor biológico; de no prestar atención a los marcos institucionales; de no distinguir con nitidez lo vital de lo cultural, etc.

La respuesta de Américo Castro no se hizo esperar. A finales de 1953 publica, sin ánimo polémico y sin nombrar a sus críticos, un estudio sobre teoría histórica, "En el umbral de la historia". En 1954 aparece una nueva edición de España en su historia muy modificada: se suprime mucho del aspecto literario, se incrementa lo histórico y se establecen unos postulados teóricos. Este "nuevo libro" se imprime también con un título diferente; La realidad histórica de España. Los ataques a Sánchez-Albornoz son por lo general velados: no se le nombra, o se dan por no oídas sus críticas. En el mismo año aparecen otros dos artículos en que Castro reafirma sus supuestos teóricos: "Acerca de la histórica inseguridad de los españoles" y "La tarea de historiar". Sánchez-Albornoz, por su parte, vuelve a recordar y precisar algunas de sus ideas en "Sobre historia española", y al año siguiente publica su ya anunciada interpretación, España, un enigma histórico, dos tomos llenos de intensidad, en los que se combate sistemáticamente La realidad histórica de España, para edificar sobre lo negado una nueva interpretación. En este mismo año, 1956, Castro da a la prensa un libro sobre historiografía, Dos ensayos, donde se amplían y profundizan algunos de sus supuestos teóricos. Reafirma nuevamente su posición en "Ser y valer: dos dimensiones del pasado historiable" (1957) , y, siguiendo su costumbre, ataca las objeciones de SánchezAlbornoz sin llegar a nombrarle y sin mencionar que fue acusado de aquello contra lo que él ahora parece prevenirse. Los artículos destinados a apoyar sus teorías historiográficas se multiplican en 
los años sucesivos y en ellos se modifica, se profundiza, se amplía lo ya indicado en Dos ensayos y en La realidad histórica de España en su edición de 1954. Podemos considerar como su posición definitiva la señalada en el capítulo cuarto de $L a$ realidad... en las ediciones de 1965 y 1971.

Las consecuencias más agrias de la polémica tuvieron lugar, no obstante, en las diferencias ante aspectos singulares y concretos. De todos ellos destaca la interpretación y significación de la creencia en Santiago en la formación del pueblo español durante la Edad Media. El problema es importante, pues, mientras Castro trata de separarlo de toda connotación cristiana en sus orígenes, SánchezAlbornoz se opone enérgicamente, empeñado en encontrar los comienzos del culto en la tradición cristiana. El motivo de las discrepancias sobre la creencia en Santiago (origen dioscórido, "hermandad" de Santiago el Menor con Jesús, etc.) es ciertamente secundario si lo comparamos con su función dentro de la tesis de Américo Castro. En La realidad histórica de España de 1954 se dedicaba al tema de Santiago todo el capítulo sexto. En la edición de 1971 llega a formar los capítulos noveno y décimo. La polémica comenzó con las objeciones de Sánchez-Albornoz en "Ante España en su historia", a las cuales contestó Castro indirectamente en la primera edición de La realidad histórica de España. Sánchez-Albornoz fundamentó su posición, sin intención polémica, en el artículo "Ante la Historia compostelana" (1955), y al año siguiente, polemizando con Castro, en España, un enigma histórico, bajo el significativo título de "Santiago hechura de España y no España obra de Santiago". En el mismo año respondió Castro directamente en una interesante e inteligente defensa en el segundo de los Dos ensayos. Amplió y profundizó sus ideas nuevamente en "Santiago y los Dioscuros" (1957) con una penetrante, si no siempre científica, defensa del origen dioscórido del culto a Santiago. Este artículo pasó luego a formar parte de un libro que dedicó al tema, Santiago de España (1958), de fuerte carácter polémico. Es en este libro donde Castro arremete un tanto destempladamente contra los que se han opuesto a sus teorías (Pérez de Urbel, Ziegler, etc.) y en especial contra Sánchez-Albornoz, a quien cita siempre como "el Sr. S.-A.". Para Castro, los errores u observaciones anotadas por Sánchez-Albornoz existen sólo "en la fantasía de un crítico interesado en contradecir por contradecir, fundándose en un desconocimiento total de los hechos presentes de la realidad del pasado""24. Sus armas "han sido, ante todo, la cólera, la ligereza y el dicterio. El Sr. S.-A. me hace responsable de que él no entienda mis pensamientos, no sepa de qué estoy hablando" (ibid., p. 139). "Es enojoso tener que des-

24 A. Castro, Santiago de España, Buenos Aires, 1958, pp. 114-115. 
cender a elementalidades de escuela primaria; pero ante la pertinaz obcecación del Sr. S.-A., historiador profesional..." (p. 145). Estas citas, repetidas con excesiva frecuencia, hacen al libro impropio de su autor, quien, por otra parte, no necesitaba herir de tal modo a su ilustre contradictor para defender sus teorías.

Las réplicas de Sánchez-Albornoz no se hicieron esperar. Publicó primero un artículo en contra de la teoría de Castro, "El culto de Santiago no deriva del mito dioscórido" (1958), en el cual, además de oponerse a su concepción, hace relación de otros historiadores que la combatieron. En el mismo año apareció su libro Españoles ante la historia, colección de ensayos unidos, a pesar de la variedad, por representar lo hispano en la historia. El último capítulo, dedicado a la polémica, lleva el título "Las cañas se han tornado lanzas". Sánchez-Albornoz hace aquí un recuento de lo que él cree erróneo y proporciona una lista, bastante completa, de los críticos, historiadores, etc., que, en un momento $\mathrm{u}$ otro, han disentido de Castro, pero se guarda, a pesar de acusar de ello a Castro, de citar a tantos otros, en todos los campos, que han mostrado acuerdo con sus teorías. Es cierto que Sánchez-Albornoz nunca se sale de los límites de lo cortés, pero su actitud de superioridad y el tono irónico que emplea son también denigrántes: "Castro se dejó seducir por los cantos de sirena que creía escuchar desde el lejano ayer y cayó en la tentación de aplicar a la historia sus habituales métodos subjetivos de interpretación y de exégesis". "Alarmado, y con razón, por la idea que la lectura de mi obra pueda hacer formar de la suya -con razón porque mis alegatos han sido declarados incontrovertibles por los historiadores profesionales..."25 y a continuación cita a varios historiadores, entre ellos a Vicens Vives, a pesar de que éste, explicando su postura "en el delicado debate que planteó Castro respecto al injerto de elementos islámicos y hebraicos en la mentalidad castellana", dice muy claramente: "Aun considerando que el autor ha forzado la nota en alguna ocasión..., encuentro su teoría más aceptable que la de C. Sánchez-Albornoz... En definitiva... la hipótesis de Castro encaja más que la de su contraopinante con los documentos sobre economía, sociedad y cultura del siglo xv que yo he examinado" 26 .

Esta polémica entre pensadores y escritores tan insignes se prolongó en los años sucesivos. Sus posiciones se fueron polarizando, sacrificando la prueba científica por el hallazgo que reforzaba la postura personal. En lugar de sacar conclusiones de todo lo averiguado en las investigaciones emprendidas, con olvido de sus pro-

25 C. SÁnchez Albornoz, Españoles ante la historia, $2^{a}$ ed., Buenos Aires, 1959 , pp. 233 y 239.

26 JaIme Vicens Vives, Aproximación a la historia de España, 6* ed, Barcelona, 1969, pp. 192-193. 
pios principios, trataron solamente de buscar pruebas que fortalecieran sus ya establecidas teorías. La polémica sólo llegó a su fin ante la repentina muerte de Américo Castro el 25 de julio de 1972. El $A B C$ de Madrid, al comunicar tan sentida noticia, incluía unas palabras, llenas de emoción y sinceridad, de Sánchez-Albornoz: "PPobre Américo! tenía una mente clara y una pluma brillante. Era grande su saber y su erudición". Y termina la nota con unas palabras alegóricas que cierran la añeja polémica: "Levanto la celada, envaino la espada y con la lanza inclinada hacia la tierra me uno a quienes te acompañan al sepulcro" 27 . La carta se reprodujo nuevamente en el $A B C$ (edición semanal aérea) del 24 de agosto de 1972 bajo el significante título "Sánchez-Albornoz cierra una polémica".

Augustana College

José L. Gómez Martínez

\section{BIBLIOGRAFIA SELECTA}

\section{De AmÉrico Castro}

Algunos juicios acerca de los españoles. Ecuador $0^{\circ} 0^{\prime} 0^{\prime \prime}$, México, 1967.

Aspectos del vivir hispánico: espiritualismo, mesianismo, actitud personal en los siglos xiv al xui. Cruz del Sur, Santiago de Chile, 1949. (29 ed., muy renovada: Alianza Editoríal, Madrid, 1970).

Cervantes y los casticismos españoles. Alfaguara, Madrid, 1967.

De la edad conflictiva, 3a ed. Taurus, Madrid, 1972 (19 ed., 1961).

De la España que aún no conocia. Finisterre, México, 1971.

Dos ensayos: 1. Descripción, narración, historiografia. 2. Discrepancias y mal entender. Porrúa, México, 1956.

El pensamiento de Cervantes. Hernando, Madrid, 1925. (Nueva ed. actualizada: Noguer, Barcelona, 1971).

Ensayo de historiologia. Analogias y diferencias entre hispanos y musulmanes. F. C. Feger, New York, 1950.

España en su historia: cristianos, moros y judios. Losada, Buenos Aires, 1948.

"Español", palabra extranjera: razones y motivos. Taurus, Madrid, 1969.

Hacia Cervantes, 3a ed. Taurus, Madrid, 1967. (19 ed., 1957).

"La Celestina" como contienda literaria. Castas y casticismos. Revista de Occidente, Madrid, 1965,

La realidad histórica de España. Porrúa, México, 1954. (Es una ed. muy renovada de España en su historia; con el nuevo título hay cuatro eds.: 1954, 1962, 1966 y 1971; cada una supone una gran reelaboración con respecto a la precedente).

"La realidad histórica de España": juicios y comentarios. Porrúa, México, 1957.

La Spagna nella sua realtà storica. Trad. Giuseppe Cardillo e Letizia Falzone. Sansoni, Firenze, 1955.

27 "Emocionado testimonio de Claudio Sánchez-Albornoz", $A B C$, ed. semanal aérea, 3 de agosto de 1972, p. 27. 
L'età dei confitti. Trad. Leonardo Cammarano. Milano-Napoli, 1970.

Los españoles: cómo llegaron a serlo. Taurus, Madrid, 1965. (Reedición, muy renovada, de Origen, ser y existir de los españoles, Taurus, Madrid, 1959) .

Réalité de l'Espagne. Trad. Max Campserveux. Klincksieck, Paris, 1963.

Santiago de España. Emecé, Buenos Aires, 1958.

Semblanzas y estudios españoles. Sel. de textos y notas prels. por Juan Marichal. Princeton, 1956. (Contiene una excelente bibliografía de A. Castro).

Spanien: Vision und Wirklichkeit. Übers, von Suzanne Heintz. Kiepenheuer und Witsch, Köln-Berlin, 1957.

Teresa la Santa, Gracián y los separatismos, con otros ensayos. Alfaguara, Madrid, 1971. (Reedición renovada y muy ampliada de Santa Teresa y otros ensayos, Historia Nueva, Madrid, 1929).

The Spaniards: an introduction to their history. Transl. by Willard F. King and Selma Margaretten. University of California Press, Berkeley, 1971.

The structure of Spanish history. Transl. by Edmund L. King. Princeton University Press, Princeton, 1954.

"A note on The structure of Spanish history", Sp, 30 (1957), 222-223.

"Acerca de la histórica inseguridad de los españoles", $C C L, 1954$, núm. 5, 82-84.

"Acerca del castellano escrito en torno a Alfonso el Sabio", $F R$, 1954, núm. 4, $1-11$.

"Antiguo español fijodalgo-ibn-al-homs", $R P h, 4$ (1950-51), 47-53.

"Claridad y precisión historiográficas", $C C L, 1958$, núm. 33, 3-13.

"Cómo y por qué fue dualmente conflictiva la literatura del siglo xvi", $P S A$, 42 (1966), $229-246$.

"Con motivo de fijodalgo", NRFH, 5 (1951), 6́9-71.

“Cristianismo, Islam, poesía en Jorge Manrique”, PSA, 9 (1958), 121-140.

"Chiarezza e precisione nella storiografia", Verri, 1959, núm. 3, 12-36.

"El drama de la honra en España y en su literatura", CCL, 1959, núm. 39, 16-28.

"El enfoque histórico y la no hispanidad de los visigodos", NRFH, 3 (1949), 217-263.

"El Libro de buen amor del Arcipreste de Hita", $C L, 4$ (1952), 193-213.

"El "nosotros» de las historias", ROcc, 5 (1964), $259-282$.

"En defensa de la Editorial Porrúa", $M L N, 82$ (1967), 222-225.

"En el centenario de nuestra Asociación", $H, 50$ (1967), 919-922.

"En el umbral de la historia", NRFH, 7 (1953), 242-245.

"Ensanchamiento de las ideas acerca del hombre", CCL, 1955, núm. 10, 49-52.

"Hijodalgo, un injerto semítico en la vida española", $P S A, 20$ (1961), 9-21.

"La «novedad» y las «nuevas»", HR 20 (1952), 149-153.

"La orientalidad de los musulmanes de Al-Andalus", PSA, 7 (1957), 13-21.

"Lau tarea de historiar", CCL, 1954, núm. 4, 21-25.

"Le Sultan Saladin et les littératures romanes", Diogène, 1954, núm. 8, 18-47.

"Los españoles no han sido así como dicen los libros al uso", PSA, 38 (1965), $31-42$.

"Los visigodos no eran aún españoles", NRFH, 15 (1961), 1-3.

"Media un milenio entre las palabras España y españoles", EFil, 3 (1967), 5666. (También en $f n s, 1967$, núm. 252).

"Mozarabic poetry and Castile: a rejoinder to Mr. Leo Spitzer", CL, 4 (1952), 188-189.

"Prioridad del entender", PSA, 9 (1958), 944.

"Quelques précisions au sujet de España en su historia", BHi, 53 (1951) , 5-12.

"Razones para españoles", PSA, 26 (1962), 245-275.

"Respuesta a Leo Spitzer", NRFH, 3 (1949), 149-158.

"Santiago y los Dioscuros", PSA, 6 (1957), 233-247. 
"Ser y valer: dos dimensiones del pasado historiable", CCL, 1957, núm. 24, 3-12.

"Sobre el no querer entender nuestra historia", Íns, 1967, núm. 247.

"Sobre yo amanezco y yo anochezco", BRAE, 46 (1966), 187-190.

"Un aspecto del pensar hispano-judío", $H, 35$ (1952), 161-172.

\section{De Claudio Sánchez-Albornoz}

De ayer y de hoy. Taurus, Madrid, 1958.

España, un enigma histórico. Sudamericana, Buenos Aires, 1956; 2 ts. (Hay dos reediciones, con nuevos prólogos y correcciones menores: 1962 y 1971).

España y el Islam. Sudamericana, Buenos Aires, 1943.

Españoles ante la historia, 2a ed. Losada, Buenos Aires, 1959. (19 ed., 1958).

Miscelánea de estudios históricos. C.S.I.C., León, 1970.

"Ante España en su historia", CuHE, 1953, núm. 19, $129-145$.

"Ante la Historia compostelana", Logos, Buenos Aires, 1955, 67-95.

"Ante una versión de El collar de la paloma", CuHE, 195I, núm. 16, 130-151.

“¿De los banu al-ajmas a los fijosdalgo?”, CuHE, 1951, núm. 16, 130-145.

"El culto de Santiago no deriva del mito dioscórido", CuHE, 1958, núm. 28, $5-42$.

"El nombre de Castilla", EMP, 2 (1951), 629-641.

"Originalidad creadora del Arcipreste. Frente a la última teoría sobre el Buen amor", CUHE, 1960, núms. 31/32, 275-289.

"Panorama general de la romanización de Hispania", RUBA, 1 (1956), 37-74.

"Reconquista de la «Reconquista" (carta abierta a Luis Araquistain)", $C C L$, 1959, núm. 35, 63-68.

"Sobre historia española", CCL, 1954, núm. 5, 75-81. 